\title{
Increased Notching of the Corpus Callosum in Fetal Alcohol Spectrum Disorder: A Callosal Misunderstanding?
}

\author{
(D)E. Schneble, (D). Lack, (D) M. Zapadka, (D).M. Pfeifer, (DD.M.E. Bardo, (D). Cagley, (D). Acharya, (D)A.P. Klein, M. Balla,
} (D).T. Obayashi, (DD. Ross, (DD.R. Pettersson, and (D).M. Pollock

\begin{abstract}
BACKGROUND AND PURPOSE: In the medicolegal literature, notching of the corpus callosum has been reported to be associated with fetal alcohol spectrum disorders. Our purpose was to analyze the prevalence of notching of the corpus callosum in a fetal alcohol spectrum disorders group and a healthy population to determine whether notching occurs with increased frequency in the fetal alcohol spectrum disorders population.
\end{abstract}

MATERIALS AND METHODS: We performed a multicenter search for cases of fetal alcohol spectrum disorders and included all patients who had a sagittal T7-weighted brain MR imaging. Patients with concomitant intracranial pathology were excluded. The corpus callosum was examined for notches using previously published methods. A $\chi^{2}$ test was used to compare the fetal alcohol spectrum disorders and healthy groups.

RESULTS: Thirty-three of 59 patients with fetal alcohol spectrum disorders (0-44 years of age) identified across all centers had corpus callosum notching. Of these, 8 had an anterior corpus callosum notch (prevalence, 13.6\%), 23 had a posterior corpus callosum notch (prevalence, 39\%), and 2 patients demonstrated undulated morphology (prevalence, 3.4\%). In the healthy population, the anterior notch prevalence was $139 / 875$ (15.8\%), posterior notch prevalence was 378/875 (43.2\%), and undulating prevalence was $37 / 875$ (4.2\%). There was no significant difference among the anterior $(P=.635)$, posterior $(P=.526)$, and undulating $(P=.755)$ notch prevalence in the fetal alcohol spectrum disorders and healthy groups.

CONCLUSIONS: There was no significant difference in notching of the corpus callosum between patients with fetal alcohol spectrum disorders and the healthy population. Although reported to be a marker of fetal alcohol spectrum disorders, notching of the corpus callosum should not be viewed as a specific finding associated with fetal alcohol spectrum disorders.

ABBREVIATIONS: $\mathrm{CC}=$ corpus callosum; FAS $=$ fetal alcohol syndrome; FASD $=$ fetal alcohol spectrum disorders

ᄃetal tal alcohol syndrome (FAS) was first described $>45$ years ago $^{1}$ with detrimental effects of prenatal alcohol exposure on the developing brain that are now well-known. ${ }^{2-5}$ The nondiagnostic umbrella term, fetal alcohol spectrum disorders (FASD), is

Received October 8, 2019; accepted after revision February 10, 2020.

From the Departments of Radiology (E.S., D.R.P., J.M.P.), and Neurological Surgery (J.T.O., D.R.), Oregon Health \& Science University, Portland, Oregon; Operative Care Division (D.R.), Portland Veterans Administration Hospital, Portland, Oregon; Department of Radiology (C.L., M.Z.), Wake Forest University, Winston-Salem, North Carolina; Department of Radiology (C.M.P.), University of Texas Southwestern Medical Center, Dallas, Texas; Department of Radiology (D.M.E.B.), Phoenix Children's Hospital, Phoenix, Arizona; Department of Radiology (J.C.), Legacy Emanuel, Portland, Oregon; Department of Radiology (J.A.), University of Southern California, Keck School of Medicine, Los Angeles, California; and Department of Radiology (A.P.K., M.B.), Medical College of Wisconsin, Milwaukee, Wisconsin.

Please address correspondence to Jeffrey M. Pollock, MD, Department of Radiology, Oregon Health \& Science University, 3181 SW Sam Jackson Park Rd CR 135, Portland, OR, 97239; e-mail: pollockj@ohsu.edu

http://dx.doi.org/10.3174/ajnr.A6475 used to describe the spectrum of disorders occurring from in utero alcohol exposure. Estimated to affect approximately 2\%$5 \%$ of live births in the United States, Canada, and Western Europe, ${ }^{6}$ the range of neuropsychologic deficits associated with FASD is independent from formal FAS diagnostic criteria, which mandate the presence of midline craniofacial anomalies. ${ }^{7}$ Instead, dysmorphology of intracranial midline structures such as the corpus callosum (CC) are implicated in FASD in addition to other neurocognitive and psychiatric disorders. ${ }^{3,4,8-11}$

The CC is the largest white matter tract in the brain and is an integral structure in the transmission and synthesis of complex information between the 2 hemispheres. The CC may be disproportionally affected by prenatal alcohol exposure given that most callosal fibers are formed in utero during a period of rapid growth between 12 and 16-20 weeks of gestation. ${ }^{12,13}$ Although the total number of callosal fibers is fixed at birth, this structure continues to develop in the postnatal period due to fiber myelination, 

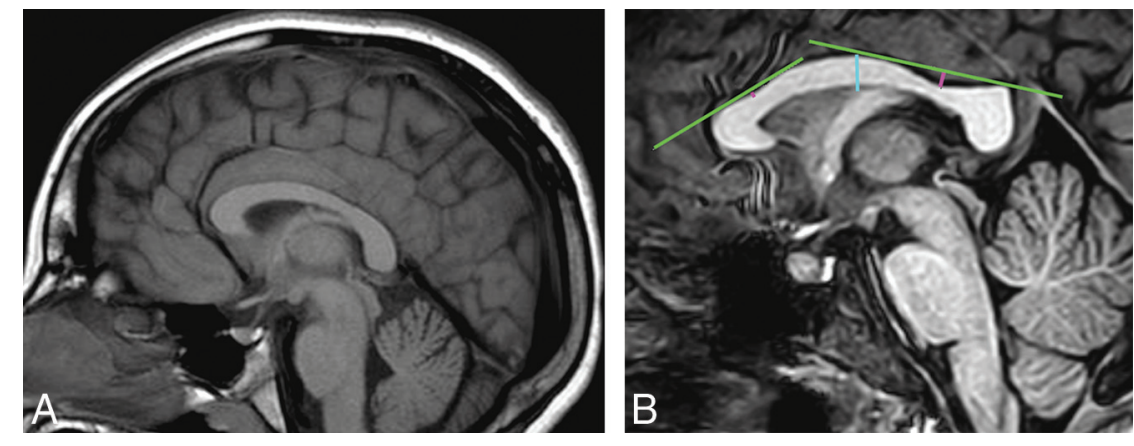

FIGURE. Midsagittal T7-weighted images. A, A normal corpus callosum with no notch. $B, A$ corpus callosum with anterior and posterior notches measuring 1 and $3 \mathrm{~mm}$ in depth (pink lines), respectively. A "notch" was defined as a depression in the dorsal surface whose depth was at least $1 \mathrm{~mm}$ from a tangential green line to the surface of the CC. Notches are classified as either anterior or posterior on the basis of their relationship to the midcallosal body (blue line).
Subjects were obtained from an ICD10 search of the electronic medical record for an FASD diagnosis with available MR imaging examinations of the brain that met the inclusion criteria. Imaging was reviewed and patients were excluded for any intracranial abnormality including but not limited to tumor, stroke, infection, migrational or structural abnormalities to include partial or complete corpus callosum dysgenesis, and surgery.

All MR imaging was performed using $1.5 \mathrm{~T}$ or $3 \mathrm{~T}$ machines. T1-weighted sagittal slices were obtained with 1 - to 4 mm section thickness. A team of neuroradiologists from 7 medical centers throughout the United States visually redirection, and pruning throughout the first 2 decades of life. ${ }^{14,15}$ These varying rates and timing of CC component development result in a dynamic morphology throughout both gestation and early life, ${ }^{16,17}$ with additional alterations in CC morphology visualized throughout the life span. ${ }^{18-20}$

The clarity of corpus callosum visualization with MR imaging lends itself to statistical shape analysis, a field that is used in the US court system for legal defense. ${ }^{21}$ A 1995 article by Riley et $\mathrm{al}^{8}$ remains frequently cited in the medicolegal literature for establishing focal abnormalities of the CC as part of the FAS spectrum. ${ }^{21}$ Subsequent literature suggests focal thinning or concavity of the CC, which the current authors refer to as "notching," to be an indicator of brain damage from fetal alcohol exposure. ${ }^{21,22}$

The goal of this study was to further characterize the CC in the FASD population. Specifically, we sought to compare the prevalence of dorsal notching in a patient group with known FASD with the prevalence of dorsal notching in a population with no history of FASD and no gross abnormalities on brain MR imaging. Recent studies have suggested that focal concavities along the anterior and posterior surfaces of the CC are manifestations of normal growth and development. ${ }^{23,24}$ An analysis of $>1600$ brain MR imaging studies by Krause et $\mathrm{al}^{24}$ showed a CC notch in $50 \%$ of men and women. In addition, the lack of identified notches in the first week of life led the authors to suggest that notching is an acquired characteristic of normal CC development. Furthermore, the overall prevalence of notching was found to be greater than the expected prevalence of FASD, suggesting that notching is a normal morphologic feature and not pathognomonic of FASD. ${ }^{24}$

Building on recent work $^{23,24}$ examining CC notching in a healthy population, we used the same methodology to characterize the dorsal contour of the corpus callosum within an FASD group. The goal of this study was to determine whether notching along the dorsal surface of the CC is more prevalent in FASD compared with a healthy population.

\section{MATERIALS AND METHODS}

This retrospective, multicenter study was approved by the respective institutional review board with a waiver of patient consent. inspected the dorsal surface of each CC on a midline sagittal T1weighted image obtained at respective institutions. The morphology of each corpus callosum was assessed using a previously described protocol. ${ }^{24}$ A CC was designated "normal" if the dorsal surface contained no notching (Fig 1A). A "notch" was defined as a focal concavity in the dorsal surface, the depth of which was at least $1 \mathrm{~mm}$ from a tangential line to the surface of the CC (Fig $1 B)$. The location of the notch was recorded as anterior or posterior with the midbody of the CC separating the 2 locations. The $\mathrm{CC}$ was considered "undulating" if $>2$ notches involving both the anterior and posterior CC were present. Each center submitted measurements and anonymized images of their cases.

Age-matched data from prior work analyzing 1639 unique brain MR imaging studies with normal findings using identical methodology and inclusion and exclusion criteria were used to define the radiographically healthy control group with no clinical history of FASD. ${ }^{24}$

Statistical analysis with a $\chi^{2}$ test was performed to determine whether there were significant differences among anterior, posterior, and undulating notch prevalence in FASD compared with a healthy population. Values were calculated in Excel (Microsoft, Redmond, Washington) and were then imported into SPSS Statistics, Version 24 (IBM, Armonk, New York). Statistical analysis was performed using SPSS. $P$ values $<.05$ were considered significant.

\section{RESULTS}

One hundred forty-one patients with a clinical diagnosis of FASD were initially identified. Ninety-six of those patients had adequate MR imaging examination findings. Fifty-nine of the patients with FASD (0-44 years of age; mean, 11.5 years) with MR imaging met all the inclusion and exclusion criteria. A spectrum of structural abnormalities was the most common reason for the 37 exclusions (23 dysgenesis of the CC, 8 cortical migration abnormalities, 3 Chiari 1 malformations, and 3 cases of periventricular leukomalacia). Eight notches of the anterior CC were identified in the FASD group (prevalence, 13.6\%). Twenty-three patients had

\section{Statistical Analysis}




\begin{tabular}{lccc}
\hline & & $\begin{array}{c}\text { FASD } \\
\text { Non-FASD } \\
\text { Control } \\
\text { Group }\end{array}$ & $\begin{array}{c}\text { (Excluded } \\
\text { Due to } \\
\text { Structural } \\
\text { Abnormality) }\end{array}$ \\
\hline Brain MR imaging studies reviewed (No.) & 59 & 875 & 37 \\
Brain MR imaging studies with notches & $33(55.9 \%)$ & $554(63.3 \%)$ & $11(29.7 \%)$ \\
$\quad$ (No.) (\%) & $23(39 \%)$ & $378(43.2 \%)$ & $10(27 \%)$ \\
Posterior position (No.) (\%) & $8(13.6 \%)$ & $139(15.8 \%)$ & $1(2.7 \%)$ \\
Anterior position (No.) (\%) & $2(3.4 \%)$ & $37(4.2 \%)$ & $0(0 \%)$ \\
Undulating, >2 notches (No.) (\%) & & & \\
\hline
\end{tabular}

pathologic, feature of normal development. These findings are corroborated by our multicenter analysis of an FASD population, which demonstrates that the prevalence of notching is not increased in the FASD group compared with an age-matched control population. Thus, the neuroradiologist should recognize notching as a common finding on brain MRIs and not a pathologic finding specific for FASD.

MR imaging has served as a tool to describe brain morphologic differences in FASD populations in relation to associated

a posterior CC notch (prevalence, 39\%). Two patients demonstrated undulated morphology (prevalence, 3.4\%). In the healthy age-matched control group, the anterior notch prevalence was $139 / 875$ (15.8\%), the posterior notch prevalence was $378 / 875$ (43.2\%), and the undulating prevalence was $37 / 875$ (4.2\%). There was no significant difference among the anterior $(P=.635)$, posterior $(P=.526)$, and undulating $(P=.755)$ notch prevalence in the FASD and healthy groups (Table).

We also reviewed the 37 patients with FASD who were initially excluded due to structural abnormalities and found 1 anterior notch (prevalence, 2.7\%) and 10 posterior notches (prevalence, $27 \%$ ). There was no significant difference in the FASD groups designated "structurally normal" and having "structurally abnormal" findings between the anterior $(P=.076)$ and posterior $(P=.230)$ notch prevalence. There was no significant difference between the prevalence of anterior $(P=.086)$ and posterior $(P=.129)$ notches among the FASD group, the FASD group with structural abnormalities, and healthy age-matched controls.

\section{DISCUSSION}

In our multicenter study population, there was no significant difference in CC notching between our subjects with FASD and healthy populations. Although the developing CC may be susceptible to the effects of prenatal alcohol exposure, focal notching was not found to have an increased prevalence in our FASD population compared with age-matched controls. These findings conflict with the medicolegal use of MR imaging to suggest that notching of the CC is evidence of an individual having FASD. ${ }^{21}$

In an era in which the US judicial system is increasingly willing to accept brain imaging as evidence of injury or pre-existing conditions, the importance of defining both normal and pathologic morphology is paramount. This study builds on recent work examining MR imaging characteristics of the CC that found dorsal notching as both an acquired and dynamic feature of normal corpus callosum development. This prior examination of 1639 MR imaging examinations with normal findings also served as the age-matched control group of the current study. In this study, the authors noted increasing prevalence $(P<.001)$ and depth $(P=.028)$ of anterior notching with increasing age as well as decreasing prevalence of posterior notching as age increased $(P<.001) .^{24}$ Although the study of Krause et $\mathrm{al}^{24}$ was not adequately powered to perform a dedicated cohort study of the FASD population, lack of notching in the first week of life led the authors to suggest that notching can be an anatomic, not cognitive deficits. ${ }^{2-4,25}$ However, much remains unknown regarding the impact of prenatal alcohol exposure on the developing brain without a diagnostic pattern of abnormalities yet available on MR imaging examinations. ${ }^{26}$ A single anatomic feature such as focal thinning or notching is unlikely to be a suitable marker of FASD, given the complex process involving the development and maturation of the corpus callosum. Whereas the effects of intrauterine alcohol exposure occur on a spectrum, so do the morphologic features of the corpus callosum within a healthy population.

A limitation of this study is the narrow focus of solely examining the dorsal surface of the CC. Although this is a multicenter study, the regional and global characteristics that may affect CC morphology were not quantified. In addition, the current study is not a longitudinal study because patients were not tracked along their dedicated life span, a critical gap across the available MR imaging literature. ${ }^{9}$ Due to the purely radiographic nature of this study, we do not have any clinical data of the potential functional deficits of the patients or a quantitative assessment of alcohol exposure that these patients experienced in utero. Last, a retrospective review of both the healthy and FASD populations leads to an inherent selection bias. These findings may be further confounded by excluding studies with concomitant pathology.

\section{CONCLUSIONS}

In the medicolegal field, focal concavity or notching has been considered a diagnostic structural finding associated with FASD. ${ }^{21}$ Whereas prior studies have suggested corpus callosum notching to be a manifestation of normal development and growth, our multicenter study sought to compare the prevalence of notching in FASD to a healthy population. Lack of a significant difference of notching between FASD and healthy groups suggests that notching of the corpus callosum should not be viewed as a specific finding associated with FASD. This study does not contradict other dysmorphias of fetal alcohol exposure but broadens prior work suggesting CC notching to be a normal anatomic feature without pathognomonic correlation to FASD.

Disclosures: Dianna M.E. Bardo-UNRELATED: Consultancy: Knonkiljke Philips NV, Guerbet*; Royalties: Thieme Publishing; Travel/Accommodations/Meeting Expenses Unrelated to Activities Listed, money paid to the individual: Knonkiljke Philips NV, Guerbet; Other: Bracco, Comments: research support.* *Money paid to the institution. 


\section{REFERENCES}

1. Jones KL, Smith DW, Ulleland CN, et al. Pattern of malformation in offspring of chronic alcoholic mothers. Lancet 1973;1:1267-71 CrossRef Medline

2. Archibald SL, Fennema-Notestine C, Gamst A, et al. Brain dysmorphology in individuals with severe prenatal alcohol exposure. Dev Med Child Neurol 2001;43:148-54 Medline

3. Sowell ER, Mattson SN, Thompson PM, et al. Mapping callosal morphology and cognitive correlates: effects of heavy prenatal alcohol exposure. Neurology 2001;57:235-44 CrossRef Medline

4. Yang Y, Phillips OR, Kan E, et al. Callosal thickness reductions relate to facial dysmorphology in fetal alcohol spectrum disorders. Alcohol Clin Exp Res 2012;36:798-806 CrossRef Medline

5. Holzman C, Paneth N, Little R, et al. Perinatal brain injury in premature infants born to mothers using alcohol in pregnancy: Neonatal Brain Hemorrhage Study Team. Pediatrics 1995;95:66-73 Medline

6. May PA, Baete A, Russo J, et al. Prevalence and characteristics of fetal alcohol spectrum disorders. Pediatrics 2014;134:855-66 CrossRef Medline

7. Mattson SN, Riley EP, Gramling L, et al. Neuropsychological comparison of alcohol-exposed children with or without physical features of fetal alcohol syndrome. Neuropsychology 1998;12:146-53 CrossRef Medline

8. Riley EP, Mattson SN, Sowell ER, et al. Abnormalities of the corpus callosum in children prenatally exposed to alcohol. Alcohol Clin Exp Res 1995;19:1198-1202 CrossRef Medline

9. Donald KA, Eastman E, Howells FM, et al. Neuroimaging effects of prenatal alcohol exposure on the developing human brain: a magnetic resonance imaging review. Acta Neuropsychiatr 2015;27:25169 CrossRef Medline

10. Norman AL, Crocker N, Mattson SN, et al. Neuroimaging and fetal alcohol spectrum disorders. Dev Disabil Res Rev 2009;15:209-17 CrossRef Medline

11. Barkovich AJ, Kjos BO, Jackson DE Jr, et al. Normal maturation of the neonatal and infant brain: MR imaging at 1.5 T. Radiology 1988;166:173-80 CrossRef Medline

12. Achiron R, Achiron A. Development of the human fetal corpus callosum: a high-resolution, cross-sectional sonographic study. Ultrasound Obstet Gynecol 2001;18:343-47 CrossRef Medline

13. Malinger $G$, Zakut $H$. The corpus callosum: normal fetal development as shown by transvaginal sonography. AJR Am J Roentgenol 1993;161:1041-43 CrossRef Medline
14. Knyazeva MG. Splenium of corpus callosum: patterns of interhemispheric interaction in children and adults. Neural Plast 2013;2013:639430 CrossRef Medline

15. Vannucci RC, Barron TF, Vannucci SJ. Development of the corpus callosum: an MRI study. Dev Neurosci 2017;39:97-106 CrossRef Medline

16. Tanaka-Arakawa MM, Matsui M, Tanaka C, et al. Developmental changes in the corpus callosum from infancy to early adulthood: a structural magnetic resonance imaging study. PLoS One 2015;10: e0118760 CrossRef Medline

17. Luders $\mathrm{E}$, Thompson PM, Toga AW. The development of the corpus callosum in the healthy human brain. J Neurosci 2010;30:10985-90 CrossRef Medline

18. Allen LS, Richey MF, Chai YM, et al. Sex differences in the corpus callosum of the living human being. J Neurosci 1991;11:933-42 Medline

19. Doraiswamy PM, Figiel GS, Husain MM, et al. Aging of the human corpus callosum: magnetic resonance imaging in normal volunteers. J Neuropsychiatry Clin Neurosci 1991;3:392-97 CrossRef Medline

20. Hayakawa K, Konishi Y, Matsuda T, et al. Development and aging of brain midline structures: assessment with MR imaging. Radiology 1989;172:171-77 CrossRef Medline

21. Mardia K, Bookstein F, Kent J. Alcohol, babies and the death penalty: saving lives by analysing the shape of the brain. Significance 2013;10:12-16 CrossRef

22. Bookstein FL, Connor PD, Huggins JE, et al. Many infants prenatally exposed to high levels of alcohol show one particular anomaly of the corpus callosum. Alcohol Clin Exp Res 2007;31:868-79 CrossRef Medline

23. Simpson LN, Schneble EJ, Griffin ED, et al. Morphological changes of the dorsal contour of the corpus callosum during the first two years of life. Pediatr Radiol 2019 Dec 16. [Epub ahead of print] CrossRef Medline

24. Krause KL, Howard D, Pettersson DR, et al. Defining the normal dorsal contour of the corpus callosum with time. AJNR Am J Neuroradiol 2019;40:86-91 CrossRef Medline

25. Moore EM, Migliorini R, Infante MA, et al. Fetal alcohol spectrum disorders: recent neuroimaging findings. Curr Dev Disord Rep 2014;1:161-72 CrossRef Medline

26. Treit S, Jeffery D, Beaulieu C, et al. Radiological findings on structural magnetic resonance imaging in fetal alcohol spectrum disorders and healthy controls. Alcohol Clin Exp Res 2020;44:455-62 CrossRef 